\title{
Preservice Teachers' Discursive Constructions of Cultural Practices in a Multicultural Telecollaboration
}

\author{
Baburhan Uzum \\ Sam Houston State University \\ U. S. A. \\ Bedrettin Yazan \\ The University of Alabama \\ U.S. A. \\ Netta Avineri \\ Middlebury Institute of International Studies at Monterey \\ U. S. A. \\ Sedat Akayoglu \\ Abant Izzet Baysal University \\ Turkey
}

\begin{abstract}
The study reports on a telecollaboration exchange between two teacher education classes in the United States and Turkey. In synchronous and asynchronous conversations, preservice teachers (PTs) engaged in social justice issues and made discourse choices that captured culture(s) and communities as diverse or essentialized. These choices were affected by PTs' positionings and impacted how PTs connected to individuals only and/or to broader society. PTs asked questions that created space for critical discussions and facilitated awareness of diversity, yet sometimes led to overgeneralizations. The study has implications for designing telecollaborations that promote language and practices to unpack the issues of social justice.
\end{abstract}

KEYWORDS: telecollaboration, social justice, preservice teachers, positioning, discursive construction

Teacher Education for Social Justice

Telecollaboration: A Discursive Space to Discuss Issues of Social Justice and Equity Theoretical Framework Methods

Findings

Discussion

Conclusion and Implications

Limitations and Future Directions

Notes

Acknowledgments

References

Author Contact 
Telecollaboration is an Internet-based collaborative practice for intercultural exchange between individuals from different ethnolinguistic/national backgrounds and geographically remote locations (Guth \& Helm, 2010). It is coordinated in an institutional setting to develop participants' language skills and intercultural communicative competence (Byram, 1997) by engaging in structured online tasks (Guth \& Helm, 2010). Originally developed to cater to language learners (e.g., projects such as Clavier, Teletandem, Cultura, Cultnet), telecollaboration's scope has been extended to include preservice and practicing teachers (Guth \& Helm, 2010). For example, in Dooly's (2011) telecollaboration, two groups of preservice teachers (PTs) from Spain and the U.S. engaged in intercultural communication tasks and developed virtual communities of practice as English language teaching professionals. Despite its expanding scope, most telecollaborative tasks have not tackled the difficult critical questions regarding the reasons for and ramifications of social inequities and have thus resulted in "trivial exchanges" (O'Dowd, 2016a, p. 297). Therefore, telecollaboration has recently been critiqued for diverging from its transformative goal of promoting critical conversations addressing social, political, and historical issues, as well as social injustices in participants' contexts (O'Dowd, 2016a). The project reported in this paper was designed to accomplish this transformative goal as part of PTs' professional preparation. This project involved an eight-week online exchange between a group of PTs in Bolu, Turkey, and one in Texas, U.S., who discussed issues of multicultural education, social justice, and equity through synchronous and asynchronous online tasks.

\section{Teacher Education for Social Justice}

Preparing teachers as social justice agents is primarily tasked to teacher education programs since it requires PTs to refashion their ideological and professional identities (McDonald, 2005; Zeichner, 2009). Earlier research mentions three types of preservice teachers, attitudinally and dispositionally (Garmon, 2004; Mills \& Ballantyne, 2016). Some PTs enter teacher education programs with a degree of commitment to social justice, and it is relatively easy for them to apply their beliefs and dispositions to teaching practice (Chubbock, 2010). Some PTs have no explicit commitment to social justice, but they are receptive to developing such commitment throughout teacher education. A third group of PTs exhibits reluctance or resistance to the principles of social justice in teaching (Mueller \& O'Connor, 2007).

To educate PTs for social justice, teacher educators can use a couple of overlapping strategies. In some teacher education practices, PTs reflect on their own positioning in relation to privilege and marginalization, as well as the social, cultural, political, and economic origins and reproductions of injustices (de Freitas, 2008; Frederick, Cave, \& Perencevich, 2010). Teacher educators also attempt to effect change in PTs through "pedagogy of discomfort" (Boler \& Zembylas, 2003; de Freitas \& McAuley, 2008). With this approach, PTs can challenge "unconscious complicity with hegemony" (Boler \& Zembylas, 2003, p. 111) as they inquire into 
their emotional investment in the "inscribed habits of inattention" (Boler, 1997, p. 417). Both reflecting on social injustices and pedagogy of discomfort can impact PTs' online intercultural exchanges. The current study aimed to promote PTs' personal inquiry into the roots of injustices in their society and "discomforting emotional labor" (Boler \& Zembylas, 2003, p. 116) through first-hand engagement with otherness (Byram, 1997) and their reflection on this engagement. The telecollaborative project engaged PTs in discussions on social justice issues relating to gender, language variety, socio-economic status, and religion in their sociopolitical contexts via synchronous and asynchronous conversations.

\section{Telecollaboration: A Discursive Space to Discuss Issues of Social Justice and Equity}

Recently, increasing numbers of teacher education classes have adopted intercultural telecollaboration to help PTs develop beliefs and dispositions to work with linguistically and culturally diverse students (Dooly, 2011; Menard-Warwick, Heredia-Herrera, \& Palmer, 2013; Tanghe \& Park, 2016). As a cost-efficient substitute for study/teach abroad programs, telecollaboration affords the opportunity for PTs to interact with peers from other cultural contexts (Chun, Kern, \& Smith, 2016). In telecollaborative activities, participants are expected to practice the target language, gain knowledge about other cultures, reflect on their own cultures, and develop competence to evaluate social and political perspectives and practices critically (O'Dowd \& Lewis, 2016). Participants are expected to understand that all cultural beliefs, values, priorities, and practices are historically and contextually-bound constructions and, as such, are equally viable; they are also expected to shape their behaviors based on this understanding within and across cultures.

Despite its rising popularity, telecollaboration has also received significant criticism from scholars who argue that telecollaborative tasks tend to be limited to superficial discussion topics (e.g., festivals, food) and allow participants to avoid engaging in challenging and discomforting subjects (e.g., gender inequality, ethnic/religious marginalization) (Helm, 2013; Kramsch, 2014a, 2014b; O'Dowd, 2016a). Originally, telecollaboration strove to promote transformative learning experiences involving developing critical approaches to thorny sociopolitical and historical issues and to social injustices and inequalities (Helm, 2016). Recent critical approaches to telecollaboration (O'Dowd, 2016b) refocus on this aim and specifically provide discursive and experiential spaces for participants to engage with otherness and to understand the historical, cultural, and political construction of meaning, values, and hierarchies in societies (Helm, 2016; Porto, 2014; Tcherepashenets, 2016). The project described in this paper aimed to accomplish this goal and included synchronous and asynchronous telecollaborative tasks (e.g., discussion board posts, one-on-one video conferences) that would create discursive and experiential spaces for PTs to discuss issues of social justice (e.g., gender, religion, language) in their own and in peers' sociocultural contexts. To 
understand PTs' participation in such spaces, the study addressed the following research questions:

1. How do PTs engage in and discuss multicultural education and social justice issues in a synchronous and asynchronous telecollaboration project?

2. How do PTs' language use and positionings shape the conversations on these issues in such exchanges?

\section{Theoretical Framework}

To understand PTs' interactions in this telecollaboration, we adopted "positioning theory" (Davies \& Harré, 1999) to explore how PTs positioned themselves and their interlocutors in relation to their respective sociocultural contexts. Positioning is "a discursive process whereby people are located in conversations as observably and subjectively coherent participants in jointly produced storylines" (Davies \& Harré, 1999, p. 37). In an interactional setting, speakers may not intend to engage in such positioning, but the impact of positioning might be perceived by others. Speakers use "discursive practices" to "actively produce social and psychological realities" (p. 34). Once a speaker takes up a position via their discursive choices, the images, metaphors, and storylines available in that position create the "vantage point" (p. 35) through which speakers can see the world. Speakers can imaginatively position themselves as belonging to one group and not the other, and develop "a moral system organized around the belonging" (p. 36). The act of positioning therefore takes place "in relation to a theory of the person as a certain kind of self, embodied in a pronoun grammar in which a person understands themselves as historically continuous and unitary" (pp. 36-37). Another aspect of our analysis involves "the modes of positioning," especially as related to "moral and personal positioning" (Harré \& Langenhove, 1991, p. 397). In moral positioning, speakers are perceived in relation to the actions they perform within certain moral orders, such as expectations from a professional role or group membership (e.g., teacher candidate, (non)religious, Turkish/American citizen). Personal positioning, on the other hand, involves "individual properties and particularities," such as deviance from the expectations present in moral positioning. Speakers simultaneously position themselves (and are positioned) in both moral and personal positionings. However, the personal positioning may become "more prominent" (p. 398) with the emergence of increased particularities that cannot be explained solely by the roles in moral positioning.

The use of personal pronouns (e.g., $l$, we, you, they) is central in the positioning and discursive constructions of self and other. For example, the first person plural pronoun we can be used generically to refer to "people in general" and may be perceived as "mass speaking" (Mühlhausler \& Harré, 1990, p. 201) as in the example: "We live in an age of immense changes" (Quirk, Greenbaum, 
Leech, \& Svartvik, 1985, p. 353), or can be used personally, indexing a speaker and hearer: "We have a lot to talk about, you and I" (p. 355). While the generic we includes the speaker(s), hearer(s), and others together in its scope (i.e., s+, h+, $\mathrm{o}+$ ), thereby referring to "all people," rhetorical we is used "in the collective sense of the nation" as in the example: "We neglected our poor as we amassed wealth" (p. 350), and may include only the speaker(s) (s+, h-, o-) or speakers and others $\left(\mathrm{s}+, \mathrm{h}-, \mathrm{O}^{+}\right)$, ranging in its inclusiveness and depending on the interlocutors present in the intercultural exchange (Uzum, 2013). Personal you directly refers to a hearer in an interaction: "You can stop writing now," while generic you can be used as an equivalent of one such as: "You can always tell what she is thinking" (Quirk et al., p. 354), or to invite listeners to imagine themselves in a described situation. Finally, personal they has a specific referent: "The children went to bed; they are asleep now," while generic they may designate an unknown entity, the mysterious forces which appear to control the ordinary citizen's life: 'the authorities,' 'the media,' 'the government', etc." (p. 354). In addition, generic pronouns such as we and they can be used to imagine nation-based communities in inclusive or exclusive ways, such as "Turks" and "Americans," through positionings as insiders or outsiders. In intercultural exchanges, this function of generic pronouns is similar to indefinite pronouns, such as everybody and nobody. Indefinite pronouns "lack the element of definiteness which is found in the personal, reflexive, possessive, and demonstrative pronouns" (p. 376). They are quantitative, and can have a universal or partitive meaning. In other words, they can be used to create a "universal" meaning through "all and each (of)" or partitive meaning through "some (of)" or "many (of)" (p. 380). Using universal or partitive references, speakers can create communities, and position themselves in relation to these imagined communities (p. 381).

We used positioning theory and indexical use of pronouns as an interpretive framework in our analysis, and explored how PTs' positionings were revealed in their discursive choices, especially in regard to how they used generic and personal pronouns and indefinite pronouns, and how they referred to their communities Then, we examined how these positionings shaped PTs' conversations in the asynchronous and synchronous exchanges.

\section{Methods}

The study is based on a semester-long telecollaborative project between two teacher education classes: a Multicultural Education course at Central City University ${ }^{1}$ in the U.S. (CCU) and a Language and Culture course at Northern Anatolia University in Turkey (NAU). The course instructors (authors) initiated the telecollaboration, and aimed to provide their students with first-hand experiences to develop intercultural communicative competence. The telecollaborative exchange was conducted using Edmodo (http://www.edmodo.com) for weekly asynchronous discussions in groups of four to six, and through Skype/Google Hangout toward the end of the semester for synchronous video conferences in 
pairs. The groups and pairs were randomly assigned, with at least two students from each cultural context in every discussion group. At the end of the project, all PTs wrote a reflection on their experience. PTs in Turkey wrote their reflections in Turkish to facilitate in-depth analysis, free from linguistic limitations. All translations were done by the authors.

Forty-eight PTs participated in the study after the approval of all human research procedures through the first author's Institutional Review Board. There were 22 participants at CCU, two males and 20 females. Three participants were African American; three were Latinx, and 16 were Caucasian. All spoke English as their first language, were studying to be elementary and secondary school teachers in the U.S., and sought state-required English as a second language certification. The participants at NAU included six males and 20 females. They spoke Turkish as their first language and had learned English as a foreign language. Although they had various ethnic backgrounds, they highlighted their national identity of "Turkishness." They were studying to become teachers of English as a foreign language.

Table 1

Weekly Discussion Prompts

Week 1 How do you define multiculturalism in your own life? How do you think your family, friends, or school is multicultural?

Week 2 Please share a memory that you identify as cultural. This could be a cultural item or activity (e.g., places, people, events, books, movies, music, and food) that resonates with you on a personal level.

Week 3 How do people in Turkey/the U.S. practice and experience religion? What is its place in schools and people's personal lives?

Week 4 How do you define gender roles of males and females in the workplace, at home, in the society in general? What are some discrimination or privilege examples where one gender might experience privilege or discrimination?

Week 5 What are some current/debated educational issues in your public schools (e.g., challenges, successes, failures)?

Week 6 What did you learn from this experience in general? Was there anything that you found especially interesting or surprising? How do you think learning about another culture like we did in this experience will help you as a teacher in the U.S./Turkey? 
The telecollaborative project was a required component of both courses, and PTs' activities were facilitated, monitored, and evaluated by the instructors. Both courses used Multicultural Education in a Pluralistic Society, by Gollnick and Chinn (2013), and supplemented with articles and videos on multicultural education. The weekly discussion prompts included the topic of the week (see Table 1) and its implications in education. Every week, PTs read the assigned readings, engaged in in-class discussions in their respective contexts, and then expanded their discussions to the asynchronous discussion boards with their telecollaborative groups.

To facilitate the discussions, an original post was due Thursdays, and partner-responses were due Sundays. PTs often cross-referenced their in-class discussions and previous discussion board posts. To allow for more freedom and discretion in writing, PTs were given instructions that prompted timely discussions, but were not provided with model writing samples. The reflections, synchronous meetings, and discussions were assigned completion grades. The synchronous meetings had some task guidelines given in class, and PTs were required to submit an audio file of the meeting.

\section{Data Collection and Analysis}

Collected between September 2015 and January 2016, the data included asynchronous discussion board posts (DB), transcripts of synchronous video conferences (VC), and reflection papers (RP). While the discussion board posts and the reflections were collected as textual data, the video conferences were submitted as video files and transcribed verbatim for analysis. The data were coded in two stages: open coding and axial coding. In the open coding, each author independently coded the data, assigning descriptive phrases "remaining open to all possible theoretical directions" (Saldaña, 2013, p. 100). In this stage, there were approximately 300 codes in the DB data and between 10 and 50 codes in each RP and VC document. Examples of codes included general or specific questions, elaborating through comparisons, cultural multiplicity, finding cultural commonalities, etc. In the axial coding, the codes were organized into categories based on the relationships among them. For example, the codes "general or specific questions" and "elaborating through comparisons" were grouped together to make up the code "strategies to expand on the conversations." Once the coding was completed, all the data sources were brought together to find recurring patterns, which became the themes presented in this paper. To increase the reliability of findings, we triangulated the data using multiple sources such as DB, VC, and RP as data points and multiple investigators such as the two instructors who had an insider perspective to the study and two external authors who brought an outsider perspective to the analysis. The authors met frequently to compare the codes and findings (Merriam \& Tisdell, 2016). 


\section{Findings}

In the synchronous and asynchronous conversations, PTs engaged with critical topics in different ways, based on the platform, and made discursive choices, revealing their positionings in relation to their sociocultural contexts. In their narratives, PTs positioned themselves and their interlocutors as unique individuals through personal positioning or as cultural representatives through group membership in moral positioning (e.g., members of groups defined by nationality, religion, and/or gender, etc.). More specifically, through personal positioning, PTs shared stories from their biographical experiences, and the scope of the conversations was limited to themselves. In moral positioning, PTs' narratives started from their personal experiences but extended to broader society and their position in it, enabling conversations on social justice issues in a broader perspective (e.g., how Turkish females experience religion in Turkey). We found that personal positioning was reflected by personal pronoun use, while moral positioning led to generic pronoun use. Moral positioning created space for critical discussions and facilitated awareness of diversity, but also sometimes led to overgeneralizations through generic frames of reference. The findings are presented under three themes: (a) language of disengagement and engagement in synchronous and asynchronous platforms, (b) generic and personal frames of references in questions, and (c) essentialization and diversity in responses. The excerpts presented here were selected for their representativeness of the data.

\section{Language of Disengagement and Engagement in Synchronous and Asynchronous Platforms}

In their discussions, PTs engaged on certain topics and explicitly or implicitly avoided others. "Language of engagement" included participants asking follow-up questions, requesting elaboration, comparing a classmate's experience with their own experiences, and raising similar topics for further discussion. "Language of disengagement" included providing assessments only (Pomerantz, 1984), agreements only (Sacks, 1987; Liddicoat, 2011), and/or moving to switch topics, including explicit avoidance. Language of disengagement seemed to manifest more often with topics that could be seen as politically charged or uncomfortable, especially in synchronous meetings.

In a synchronous meeting between Mary and Ipek, Mary asked a question that she had created based on the class assignment. Mary, then, positioned herself as uncomfortable talking about politics in her personal life and explained the reasons:

Mary: Okay. How do you feel about your government there in Turkey?

Ipek: Actually people are peaceful and there is nothing bad or terrible about terrorism or war or I don't know economic or low economic. Everything is 
good now. I have no problem with government but it could be much more better I think. Because it has potential but they don't use it.

Mary: Yes.

Ipek: So how about you? What do you think about your government?

Mary: Oh gosh. There is so. Personally like, me, I don't like to go into government or politics or anything like that because it's a very difficult topic to talk about. It's very... something to talk about because when you have a lot of people's opinions at one time it causes conflict. We have freedom of speech so people can say what they want when they want so it causes people to get in arguments and stuff like that. But I mean I'm here so apparently they are doing something right.

Ipek: I got it. (VC, Nov 19, 2015)

When Ipek asked Mary what she thought about your (American) government, Mary explicitly avoided talking about government and politics, citing freedom of speech and adding that different opinions might cause conflicts and arguments. She hedged by focusing on her own experience ("personally like, me, I don't like") alongside generic statements ("it's a very difficult topic to talk about"). Generic pronoun usage alternated between inclusive we and exclusive they to refer to Americans. It seems that both PTs wanted the other to feel comfortable in the conversation and were quick to agree with each other's points, aligning with the tone of the conversation set by their partners (Uzum, 2010). This contributed to an impression of sameness across the contexts instead of exploring any potential differences.

In her final reflection on the telecollaboration experience, Mary stressed the similarities she shared with Ipek:

I had a real good connection with Ipek because she was a lot like me. We spent the hour on Skype mostly laughing at just random questions we had and we really hit it off. I learned a lot about her and her culture but at the same time I just found a friend who is just like me that lives across the world....Doing this assignment has opened my mind to look at similarities rather than differences. It has changed my perspective on the world. (Mary, RP, Nov.18, 2015)

Ipek on the other hand focused on more general statements about human beings and diverse perspectives:

No matter what people's gender, religion, and color is, our attitude toward them should always be humanistic and free from preconceptions. The content that popular media shows, especially those involving wars and politics create preconceptions. We need to get over these. There are multiple and diverse perspectives outside waiting to be discovered, and they are all very useful. (Ipek, RP, Jan.15, 2016)

Both Mary and Ipek discussed the relevance of perspectives. While Mary focused on the specific interaction with Ipek through personal positioning, Ipek discussed 
the importance of combatting misconceptions and discovering new perspectives through moral positioning. This navigation between personal and moral positions resonates with other examples as well.

In a late-semester synchronous meeting, Kelsey told Binnur about how she volunteered at a safe house helping abused women. She then continued to discuss various hobbies:

Kelsey: My free time. I volunteer a couple hours a week at this place called the safe house. Which is for women who have like been abused and what else do I do? I watch a lot of Netflix. I watch a lot of TV. And I just hang out with my friends. My roommate is my best friend. And we went to high school together so I pretty much just hang out with her and my dog.

Binnur: That's sweet. What TV shows do you watch? I watch a lot of TV shows from America. What do you watch? (VC, Nov. 21, 2015)

In her response to Kelsey, Binnur missed an opportunity to deepen her understanding by not asking questions about Kelsey's volunteering experience at the safe house. She provided an explicit assessment ("That's sweet") and then focused on TV shows. Though there had previously been a class discussion of gender issues and inequality, the focus in this exchange remained on relatively light-hearted and personal topics. Binnur wrote in her reflection paper, "I was surprised to hear that they did volunteer activities" (Binnur, RP, Jan. 14, 2016). While Binnur and Kelsey explored established patterns of commonalities and positioned themselves as "similar to each other," these positionings remained at a personal level through individual particularities, and they did not unpack more sensitive topics such as male-female relationships.

In her final reflection, Kelsey wrote:

I was honestly extremely surprised at how similar Binnur and I were. When I would answer her questions, she would often respond "Me too!!" and I would do the same when she was answering my questions. We both really value education, plan to get married around the same age, get along with our families, have really good support systems, plan to travel to many different countries, and enjoy watching the same TV shows. Most of our differences were religious which was to be expected. (Kelsey, RP, Nov. 21, 2015)

While Kelsey reflected on the similarities she observed, Binnur commented on the difficulties she had had during the exchange and wrote:

I had a hard time expressing myself in the topic of male-female relationships and religion. For example, in terms of male-female inequities even small differences can be interpreted as major inequities. Or, in terms of religion courses at school, it can be interpreted as teachers are forcing everyone to be Muslim. (Binnur, RP, Jan. 14, 2016)

Binnur concluded that the experience tested her ability to express herself in synchronous conversations and added that the conversations helped her widen 
her horizons. Binnur found it difficult to navigate on critical topics such as malefemale relationships and religion, especially as it related to how her narratives may be perceived as "universal" or "partitive." Her difficulties could be attributed to the increased language demand created by the immediacy of synchronous meetings.

Compared to the synchronous meetings, PTs engaged more frequently on critical topics on the asynchronous discussion boards. This may be because PTs had more time to formulate their thoughts and edit their entries, without the pressure of the synchronous meetings. Mary, who had, in her VC, shared her preference not to talk about politics in her personal life, engaged asynchronously on the topic of critical education issues through her moral positioning as a student and teacher candidate. In response to Remzi's post, Mary drew parallels between the two contexts, noting similarities in the test-driven memorization approach, but also expanded on the issue:

Remzi: Racehorse is the term in Turkey which is used also for kids and students. What students learn best is to memorize as much useless information they could and pass the exams. There is nothing much about their social and intellectual aspects. In an era that even a kid can get online and reach whatever s/he wants, it is a big mistake and life consuming event to treat kids like memory sticks.... Of course this situation lead to big problems in society like being selfish. (DB, Nov. 17, 2015)

Mary: That happens here as well and it is very horrible. It's so horrible that I think we wouldn't be able to survive without technology because our minds rely on it so much. We have a computer think for us and not ourselves. We are also so worried about passing a test that we memorize and not keep the information. That is part of some of the teachers' fault because they make it seem as if test scores mean everything. (DB, Nov. 21, 2015)

Unlike in the synchronous video conference with Ipek, here, Mary engaged on the topic of education and expanded on Remzi's point about the problems in testdriven education. Mary's response went beyond a simple acknowledgment; she further developed the topic by pointing to teachers as partially responsible for testdriven instruction. Here, the language of engagement through a moral positioning included elaborating on the presented topic by comparing the two contexts and continuing the conversation. While Mary did not comment on this exchange in her final reflection, and Remzi did not submit one, this example illustrates differences in engagement across synchronous and asynchronous platforms. In the latter, both writers and readers had "the necessary time to think, find information, and compose a message deliberately" (Chun et al., 2016, p. 67), and were able to make comparisons across the two contexts (Byram, 1997). It appears that the asynchronous meetings were more likely to provide a space in which PTs could formulate their thoughts and engage on critical and social justice issues in a less face-threatening manner. 


\section{Generic and Personal Frames of Reference in PTs' Questions}

Another factor that impacted how PTs discussed social justice issues was the wording in the questions they posed to each other. The language used in framing questions in both synchronous and asynchronous platforms positioned the interlocutors as unique individuals or cultural representatives and therefore affected the response and the subsequent discussions. For example, when a PT asked, "Do you practice any religion?" or "What is your favorite holiday?" it positioned the hearer as a unique individual and therefore elicited personal narratives that were around the self (e.g., religion and me, holidays and me). However, if asked in a generic way, "What are some holidays there?" or "What religion do people practice?", the hearer was positioned as a cultural representative (e.g., Turkish/American, male/female) and was invited to talk about religion in a broader scope. While this positioning could extend the conversations beyond personal narratives and promote an awareness of diversity, it sometimes led to overgeneralizations. The moral and personal positionings through generic vs. personal framing of the questions primed the respondents to relay their own personal experiences as the norm (essentialized) or to consider experiences from different points of view (diverse, comparing self-experiences to the experiences of others). It may be useful for other practitioners to consider different positionings through discursive practices when providing guidance during intercultural and computer-mediated interactions. The following excerpts illustrate generic and personal framing in questions, and how they shaped the discussions.

In the late-semester synchronous exchange between Gary and Hatice, Gary posed a question with personal framing, positioning Hatice as a unique individual, but Hatice responded with moral positioning:

Gary: So in your life, what are some things that $y o u^{2}$ value?

Hatice: Value. The family is value in our in Turkish society. And what is value. Turkish people value honesty and they value the wants of relatives.

Gary: Okay

Hatice: Okay and ...Turkish people are also very nationalist. They value the city where you live. (VC, Nov. 19, 2015)

While Gary positioned Hatice as an individual and asked what she valued, Hatice responded to the question capturing Turkish people in its scope, using generic our and they pronouns (cf. Bührig \& ten Thije, 2006; Uzum, 2013). By alternating among various generic and personal formulations (Barnes, 2007), she created distance and closeness with both Turkish society and her interlocutor. She started by including herself in this position, but switched to a more generic frame as she self-initiated self-repair (Hayashi, Raymond, \& Sidnell, 2013) with, "in our in Turkish society."

In the same conversation, Gary and Hatice attempted to add diversity to cultural practices and acknowledge individual differences. Gary started with the 
generic statement, "y'all mentioned different religions and branches," and continued with the personal, "what do you practice," thereby focusing on a more personal position:

Gary: Okay and (inaudible) I know we hit on it a little bit. What religion do you practice? Because I know some of $y$ 'all had mentioned that there are different type kinds, branches, but what religion do you practice?

Hatice: It's Islam. Do you know Islam?

Gary: Yeah Okay.

Hatice: I am Muslim. And if you are a Muslim you must pray.

Gary: Do what?

Hatice: You must pray, you must practice praying. Okay five times in a day. You must practice...

Gary: Oh, y'all pray five times in a day?

Hatice: Yes, and also if you are a female you must wear headscarf like that. Some of the girls are wearing it and some of them are not wearing.

Gary: Yeah. So, and um some practicing like that, does that affect y'alls relationships as marriages or boyfriend girlfriend kind of thing?

Hatice: The family, the families in Turkey do not allow boyfriend your friend. But it's up to you.

Gary: So, there's really no boyfriend girlfriend it's just you find someone and get married?

Hatice: Yes you can have boyfriend but you, I can't tell it to my family very easily. (VC, Nov. 19, 2015)

In this exchange, Gary acknowledged the religious diversity that he learned about on the discussion boards and asked Hatice what she herself practices. Hatice instead took up the cultural representative position and talked about what Muslims must do. She went back and forth in her response, adding some diversity through partitive pronouns ("some of the girls are wearing head scarfs some are not"), but also made an essentialization ("families in Turkey do not allow boyfriend"). She used generic you to invite Gary to imagine himself in the situation (O'Connor, 1994; Uzum, 2013), but shifted to I when the narrative became personal and explained how she herself deviated from others ("Yes, you can have boyfriend but you I can't tell it to my family very easily"). Therefore, while Gary asked a personal question about Hatice, Hatice's generic response possibly affected how Gary learned about relationships and marriages in Turkey.

In his final reflection, Gary wrote about this exchange, and the religion and gender connection stood out to him:

I found it hard to relate to Hatice only because of gender, her being female, and me being a male, I say this because we could not relate to some topics but only give what we go through being male or female. I found that Turkish 
families are a lot stricter than in America on relationships. In America we can date whoever we want and also marry whoever we want while in Turkey, families have a lot of arranged marriages, and everything is done for them they do not have the freedom to do as they want. I am interested in learning more about Turkey.... (Gary, RP, Nov. 20, 2015)

Gary and Hatice's conversation alternated between personal and moral positions through the questions they asked as well as the responses they provided, sometimes making overgeneralizations about culture and other times focusing on complexity and diversity. Based on what Gary wrote in his reflection paper, it appears that Hatice's overgeneralizations about families in Turkey and essentializing presentation left an impression. Gary, also positioning himself as a cultural representative, drew conclusions regarding families in Turkey and families in the U.S. Although Hatice attempted to shift to a personal positioning toward the end and distinguished herself from other families in Turkey, the generic pronouns she had used in the conversation solidified her positioning as a cultural representative and perpetuated some essentializing stereotypes.

\section{Essentialization and Diversity in Responses}

Regardless of the framing in the questions, or in instances where there were no questions, PTs positioned themselves in relation to their interlocutors and to their respective cultural contexts through their discourse choices. When they talked about their culture and community in an essentializing manner, they created a community that is the same across every member in that community, and positioned themselves as a representative. On the other hand, when they acknowledged the diversity in these communities, the responses affirmed and explored diversity within that community. The essentializing approach to culture(s) and communities hurt the minority and marginalized people the most, because they were lost in this representation and their experiences and voices were not integrated into the narratives. The following excerpts illustrate essentialized and diverse framing in PTs' narratives and how such framing shaped the subsequent discussions.

In the exchanges, PTs were often positioned in a moral positioning (e.g., Turkish/American female) and as the sole cultural informant. This was prevalent in the one-on-one synchronous meetings, whereas the asynchronous discussion boards received cultural input from multiple group members. In the following synchronous meeting, Kelsey asked for confirmation of something she found online. Her observation was validated by Binnur, however in an essentializing manner, creating a single story of Turkey:

Kelsey: Oh yeah, do you guys celebrate, is Halloween considered bad over there? I googled it and found a lot of different answers. 
Binnur: Halloween. Yeah it's not welcome because it's not our it's not our festival. I don't know. It's, we don't need to celebrate it. I don't know. Yeah, our parents don't like it. It's like a party a reason to party. And our parents say you don't need to do that and it's not our, it's not a part of our culture so it's not very welcome here. Maybe in Istanbul they celebrate it, but the normal people don't do that in Turkey. Sometimes celebrities do that, but not normal people. Not much. (VC, Nov. 21, 2015)

The cultural representative positioning through generic "you guys" and passive voice in Kelsey's question is critical in this exchange. Accepting this representative position, Binnur rejected the existence of Halloween in Turkey because she did not practice it. She presented this as an overarching fact for all of Turkey except Istanbul, creating a normative picture with the term "normal people" and portraying the celebrators of Halloween as "out of the norm." In this case, Binnur highlighted markedness (Myers-Scotton, 1993) as it relates to a cultural practice that she does not view as ours. For her, Halloween becomes a symbol of insider/outsider status within Turkey, and she created distance from "that" by focusing on geography (Istanbul vs. "normal people") as well as status (celebrities vs. "normal people"). Through these discursive choices, the PTs described cultural practices while demonstrating their own positionality and navigating the class interactions.

In an asynchronous exchange between Gulay and Trisha on the topic of multiculturalism early in the semester, Gulay provided a nuanced view of diversity in Turkey, positioning herself in a minority group. Trisha asked her follow-up questions through personal positionings:

Gulay: To me, multiculturalism means that living together with many different culture, traditions, religions and races. Each person is different from each other and has different backgrounds. Adyge, Laz, Circassian, Kurds, Alevist and Turks live in together in Turkey. My origin comes from Laz but I can't speak Laz language (Lazuri) exactly. There are around 20,000 native speakers of Laz in Turkey. Many of them live in Black Sea Region.... am a Laz and my housemate is a Circassian. We are so close to each other and we love to mention about our own culture. Circassian people have generally blond hair and blue eyes and also my housemate is blonde. That's very interesting. We always respect to each other and the other people. We see ethnic diversity in everywhere and for me it's good thing.... (DB, Oct. 16, 2015)

Trisha: I notice that you said your majors were in various languages however I wanted to ask you have you ever found it hard to communicate to your housemate since their [sic] is a boundary between your culture? (DB, Oct. 19, 2015)

Gulay: Actually, no. I have never hard to communicate to my housemate. I always want to learn something from my housemate. Sometimes we can conflict each other but like I said it can also be in family. Our culture is different but general things or truths are similar to each other. (DB, Oct. 23, 2015) 
In her explanation, Gulay placed herself in both personal and moral positionings and used diversity to approach culture in Turkey. She used examples from her own biographical experiences located among other diverse experiences, opening a path for Trisha to ask a follow-up question about personal positioning as well. In contrast to the exchange between Binnur and Kelsey, Gulay did not make sweeping generalizations and explained the diversity within the country, acknowledging and honoring the existence of marginalized and minority populations.

\section{Discussion}

This telecollaboration project was created to connect PTs in the U.S. and Turkey and to provide a platform for engaging in intercultural discussions around a range of topics as a way to encourage critical consideration of social justicerelated issues in those contexts.

To address our first research question, "How do PTs engage in and discuss multicultural education and social justice issues in a synchronous and asynchronous telecollaboration project," we found that PTs engaged in social justice issues differently in synchronous and asynchronous platforms. First, PTs often positioned themselves and each other as "unique individuals" in synchronous meetings, and the narratives were mostly around their biographical experiences and particularities. Critical conversations, which seemed to take place more often through moral positionings, were less likely to occur in synchronous video conferences as compared to asynchronous discussion boards. In the former, students mostly engaged on light-hearted and less face-threatening topics (e.g., food, festivals, music, TV shows). This may be because of student-student relationships, face-saving strategies (Brown \& Levinson, 1978), language demand, and the ability to plan responses in written discussion board formats (Chun et al., 2016). Some critical conversations did take place in the asynchronous discussion boards where students had more time to formulate their thoughts in a setting without the immediacy of back-and-forth exchanges. Given the language demands of the synchronous exchanges, perhaps students feared being misunderstood and creating an unpleasant situation or leaving a negative impression. The relationship between different online formats, various positionings, and topics discussed connects with previous research on social justice topics in telecollaborative spaces (cf. Helm, 2016; O’Dowd, 2016b; Tanghe \& Park, 2016).

In answer to our second research question, "How do PTs' language use and positionings shape their conversations," we found that when PTs engaged on critical topics, they positioned themselves and their interlocutors variably as unique individuals or cultural representatives through their discursive choices (Davies \& Harré, 1999). These positionings were revealed in their narratives, especially with regard to how they used generic and personal pronouns (e.g., I, we, you, they), indefinite pronouns (e.g., all, everyone), and how they referred to their communities. In their narratives, PTs created essentialized and homogeneous 
groups (e.g., Americans/Turks) or diverse groups (e.g., some Americans/Turks). In line with a critical approach to intercultural communication, the nation-based conceptualization of communities in PTs' narratives often neglected the diversity within these communities (Kramsch, 2014a, 2014b; Uzum, Yazan, \& Selvi, 2018).

By using various framing in questions, PTs positioned interlocutors as unique individuals (inviting their biographical narratives), or as cultural representatives (eliciting responses that connect to the larger society). For example, generic framing of questions frequently resulted in the respondents providing simplified cultural generalizations that lacked diversity (e.g., practices of minority groups) and in some cases demonstrated bias and perpetuated stereotypes. In response to these stereotypical depictions, the listeners often aligned with the storyline and accepted the narrative, possibly feeling "required to conform" to be able to continue with the speaker's storyline (Davies \& Harré, 1999, p. 40). In addition, they may have wanted to focus on intercultural attitudes like curiosity, respect, and open-mindedness (Byram, 1997, 2008; Deardorff, 2006; Feng, Byram, \& Fleming, 2009) due to the telecollaboration's expressed focus on intercultural understanding (Dooly, 2011; Guth \& Helm, 2010; Menard-Warwick et al., 2013). It appears that PTs were challenged with the language demand of navigating across personal and moral positionings without making overgeneralizations. Although in their interactions PTs demonstrated a "willingness to question the values and presuppositions in cultural practices and products in [their] own environment" (Byram, 1997, p. 58), their discursive choices did not always align with this willingness, which highlights the importance of language-inuse in understanding the effectiveness of telecollaboration. PTs may also have wanted to appear non-judgmental of the other culture, therefore relying on other tools, like Google, and then asking their interlocutor to confirm or negate their findings. Since these interactions were being recorded for class and they understood the values of the telecollaboration itself, this may have restricted how deeply they were willing to explore critical issues like power, gender, and equity.

Lastly, all PTs, regardless of their context, alternated between personal and moral positionings, being uncertain whether they should talk about themselves as individuals or their experiences as group members (Turkish/American, male/female, Christian/Muslim/other) in their respective contexts. This range of positioning could reflect uncertainty and complexity associated with having these kinds of conversations in electronically mediated communication (Chun, et al., 2016). Engaging interculturally involves uncertainty, and teacher educators could help PTs navigate the process.

\section{Implications and Conclusion}

The telecollaborative project had mixed outcomes, with strengths and challenges. Intercultural telecollaboration can be an important pedagogical tool connecting teacher candidates across different cultures and engaging them in conversations about equity and social justice, allowing them to understand these 
issues better when working with students who have inequitable access to educational resources. Intercultural telecollaboration with an emphasis on social justice issues promises a mode to foster social justice and equity awareness of preservice teachers in multicultural contexts (Dooly, 2011; Helm, 2016; O'Dowd, $2016 b)$. Focused and critical conversations during the telecollaboration can help create a space to discuss the issues of social justice and equity. While conversations about foods, music, festivals, and TV shows are not less important, these could be used as introductory activities, and followed by a critical inquiry of topics in social justice and equity.

Based on the findings presented here, we believe that language skills and discourse need to be a focal component in intercultural telecollaborative exchanges. In addition, setting ground rules or collective values to foster deep, honest discussions could facilitate more in-depth engagement during the telecollaboration. Classroom discussions supporting online conversations are recommended to unpack and discuss topics of discomfort and address potential stereotypes. In intercultural telecollaboration, teacher educators should promote and demonstrate language that captures culture(s) and communities as diverse and ever-changing, and should equip PTs with strategies to be aware of their positionalities and engage with multicultural and social justice topics adopting such language. This starts with an awareness of the distinction between selfexperiences and the experiences of others in PTs' communities. Task prompts should clearly articulate the difference between personal and moral positionings and be written in a way that invites comparisons and contrasts (Byram, 1997, 2008), such as: "How do you experience religion as a female in Turkey? How does this compare to the experiences of other females in your university/city?" By focusing on cultural diversity in their exchanges, PTs may be able to learn more than that which they can find online or through other sources. PTs could record their interactions with one another and transcribe these conversations to engage in discourse analysis of their own discussions. This may allow for increased awareness and reflection on discursive practices as they engage with their classmates throughout the course.

Through intercultural tellecollaboration, PTs can gain strategies for engaging in authentic intercultural discussions, including understanding or observing another culture and critically examining those cultures in relation to one's own experiences, biases, and identities. ${ }^{3}$ This could move the intercultural conversations from interviews that may invite cultural descriptions to critical intercultural conversations that engage around complex social justice issues. Instructors could also require (and train) PTs to conduct research before their intercultural conversations, to prepare them for more nuanced conversations that do not automatically invite generalizations. PTs could then recognize how the information they glean in their research can be complemented by exchanges with those from a particular culture, and would allow them to become more critical. 


\section{Limitations and Future Directions}

While we believe the telecollaboration project helped PTs develop intercultural competence and awareness of social justice issues in their contexts, the study was not without its limitations. First of all, the eight-hour time difference made it difficult to schedule synchronous meetings, restricting the frequency of face-to-face sessions. Second, the semesters at CCU and NAU started and ended at different times, aligning only for eight weeks. Third, the synchronous meetings were not moderated. Though we believe this made PTs more comfortable, it also meant that conversations could easily deviate from the intended focal topics. Finally, while the instructors made an effort to design the courses in a similar fashion, for example using the same textbook and grading procedures, it is possible that PTs had different expectations from the telecollaboration throughout the study. In-class discussions and prompting questions in the two contexts might have led to different focal topics in the subsequent online discussions and final reflections. For future cycles of the telecollaborative project, we believe it is important for the course objectives, guidelines, and discussions to correspond with each other so that student expectations can align with the project goals in both contexts.

\section{Notes}

1. All names and places are pseudonyms.

2. Emphasis through italics added by authors.

3. Interested readers can consider UNIcollaboration to seek telecollaborative partners in higher education (https://www.unicollaboration.org)

\section{Acknowledgements}

We are grateful to Dr. Sherry Marx and the three anonymous reviewers for their comments and suggestions on the earlier versions of this paper, which significantly contributed to improving its quality. We are also thankful to the preservice teachers who took part in this telecollaboration project. Lastly, we appreciate Heather Baker for her suggestions about the language of the article.

\section{References}

Barnes, R. (2007). Formulations and facilitation of common agreement in meetings talk. Text \& Talk: An Interdisciplinary Journal of Language, Discourse \& Communication Studies, 27(3), 273-296. 
Boler, M. (1997). Taming the labile other: Disciplined emotions in popular and academic discourses. In S. Laird (Ed.) Philosophy of education (pp. 416425). Urbana, IL: Philosophy of Education Society.

Boler, M., \& Zembylas, M. (2003). Discomforting truths: The emotional terrain of understanding difference. In P. Trifonas (Ed.), Pedagogies of difference (pp. 115-138). New York, NY: Routledge.

Brown, P., \& Levinson, S. C. (1978). Universals in language usage: Politeness phenomena. In E. Goody (Ed.), Questions and politeness: Strategies in social interaction (pp. 56-311). Cambridge, UK: Cambridge University Press.

Bührig, K., \& ten Thije, J. D. (2006). Beyond misunderstanding: Linguistic analyses of intercultural communication. Philadelphia, PA: J. Benjamins.

Byram, M. (1997). The intercultural dimension in "language learning for European citizenship." In M. Byram \& G. Zarate (Eds.), The sociocultural and intercultural dimension of language learning and teaching (pp. 17-20). Strasbourg, France: Council of Europe.

Byram, M. (2008). From foreign language education to education for intercultural citizenship: Essays and reflections. Clevedon, UK: Multilingual Matters.

Chubbock, S. (2010). Individual and structural orientations in socially just teaching: Conceptualization, implementation, and collaborative effort. Journal of Teacher Education, 61(3), 197-210.

Chun, D., Kern, R., \& Smith, B. (2016). Technology in language use, language teaching, and language learning. The Modern Language Journal, 100, 6480.

Davies, B., \& Harré, R. (1999). Positioning and personhood. In: R. Harré \& L.V. Langenhove (Eds.), Positioning theory (pp. 32-52). Chichester, UK: WileyBlackwell.

Deardorff, D. K. (2006). Identification and assessment of intercultural competence as a student outcome of internationalization. Journal of Studies in International Education, 10(3), 241-266.

de Freitas, E. (2008). Troubling teacher identity: Preparing mathematics teachers to teach for diversity. Teaching Education, 19(1), 43-55.

de Freitas, E., \& McAuley, A. (2008). Teaching for diversity by troubling whiteness: Strategies for classrooms in isolated white communities. Race, Ethnicity and Education, 11(4), 429-442.

Dooly, M.A. (2011). Crossing the intercultural borders into 3rd space culture(s): Implications for teacher education in the twenty-first century. Language and Intercultural Communication, 11(4), 319-337.

Feng, A., Byram, M., \& Fleming, M. (eds.) (2009). Becoming interculturally competent through education and training. Bristol, United Kingdom: Multilingual Matters. 
Frederick, R., Cave, A., \& Perencevich, K. (2010). Teacher candidates' transformative thinking on issues of social justice. Teaching and Teacher Education, 26, 315-322.

Garmon, M. A. (2004). Changing preservice teachers' attitudes/beliefs about diversity: What are the critical factors? Journal of Teacher Education, 55(3), 201-213.

Gollnick, D. M., \& Chinn, P. C. (2013). Multicultural education in a pluralistic society. Boston, MA: Pearson Higher Education.

Guth, S., \& Helm, F. (Eds.) (2010) Telecollaboration 2.0.: Language, literacies and intercultural learning in the 21st century. Bern, $\mathrm{CH}$ : Peter Lang.

Harré, R., \& Langenhove, L.V. (1991). Varieties of positioning. Journal for the Theory of Social Behaviour, 21, 393-407

Hayashi, M., Raymond, G., \& Sidnell, J. (Eds.). (2013). Conversational repair and human understanding. Cambridge, UK: Cambridge University Press.

Helm, F. (2013). A dialogic model for telecollaboration. Bellaterra Journal, 6(2), 28-48.

Helm, F. (2016). Facilitated dialogue in online intercultural exchange. In R. O'Dowd \& T. Lewis (Eds.), Online intercultural exchange: Policy, pedagogy, practice (pp. 150-172). New York, NY: Routledge.

Kramsch, C. (2014a). Teaching foreign languages in an era of globalization. Introduction. The Modern Language Journal, 98(1), 296-311.

Kramsch, C. (2014b). Language and culture. AILA Review, 27(1), 30-55.

Liddicoat, A. J. (2011). An introduction to conversation analysis (2nd ed.). New York, NY: Continuum.

McDonald, M. A. (2005). The integration of social justice in teacher education: Dimensions of prospective teachers' opportunities to learn. Journal of Teacher Education, 56(5), 418-435.

Menard-Warwick, J., Heredia-Herrera, A., \& Palmer, D.S. (2013). Local and global identities in an EFL Internet chat exchange. The Modern Language Journal, 97(4), 965-980.

Merriam, S.B., \& Tisdell, E.J. (2016). Qualitative research. San Francisco, CA: Jossey-Bass.

Mills, C., \& Ballantyne, J. (2016). Social justice and teacher education: A systematic review of empirical work in the field. Journal of Teacher Education, 67(4), 263-276. 
Mueller, J., \& O'Connor, C. (2007). Telling and retelling about self and "others": How pre-service teachers (re)interpret privilege and disadvantage in one college classroom. Teaching and Teacher Education, 23(6), 840-856.

Mühlhausler, P., \& Harré, R. (1990). Pronouns and people: The linguistic construction of social and personal identity. Oxford, UK: Basil Blackwell.

Myers-Scotton, C. (1993). Social motivations for codeswitching: Evidence from Africa. Oxford, UK: Clarendon Press.

O'Connor, P. E. (1994). "You could feel it through the skin": Agency and positioning in prisoners' stabbing stories. Text-Interdisciplinary Journal for the Study of Discourse, 14(1), 45-76.

O'Dowd, R. (2016a). Learning from the past and looking to the future of online intercultural exchange. In R. O'Dowd \& T. Lewis (Eds.), Online intercultural exchange: Policy, pedagogy, practice (pp. 273-298). New York, NY: Routledge.

O'Dowd, R. (2016b). Emerging trends and new directions in telecollaborative learning. CALICO Journal, 33(3), 291-310.

O'Dowd, R., \& Lewis, T. (Eds.). (2016). Online intercultural exchange: Policy, pedagogy, practice. New York, NY: Routledge.

Pomerantz, A. (1984). Agreeing and disagreeing with assessments: Some features of preferred/dispreferred turn shapes. In J. M. Atkinson \& J. Heritage (Eds.), Structures of social action (pp. 57-101). Cambridge, UK: Cambridge University Press.

Porto, M. (2014). Intercultural citizenship education in an EFL online project in Argentina. Language and Intercultural Communication, 14(2), 245-261.

Quirk, R., Greenbaum, S., Leech, G., \& Svartvik, J. (1985). A comprehensive grammar of the English language. New York, NY: Longman.

Sacks, H. (1987). On the preferences for agreement and contiguity in sequences in conversation. In G. Button \& J. R. E. Lee (Eds.), Talk and social organisation (pp. 54-69). Clevedon, UK: Multilingual Matters.

Saldaña, J. (2013). The coding manual for qualitative researchers. Thousand Oaks, CA: Sage Publications.

Tanghe, S., \& Park, G. (2016). "Build[ing] something which alone we could not have done": International collaborative teaching and learning in language teacher education. System, 57, 1-13.

Tcherepashenets, N. (2016). Telecollaboration, world citizenship and the quest for the social justice: US-Mexico project. Paper presented at the Second 
International Conference on Telecollaboration in Higher Education, Trinity College Dublin, Ireland.

Uzum, B., Yazan, B. \& Selvi, A. F. (2018). Inclusive and exclusive use of we in four American textbooks for multicultural teacher education. Language Teaching Research, 22(5), 625-647.

Uzum, B. (2013). From 'you' to 'we': A foreign language teacher's professional journey towards embracing inclusive education. Teaching and Teacher Education, 33, 69-77.

Uzum, B. (2010). An Investigation of alignment in CMC from a sociocognitive perspective, CALICO Journal, 28(1), 135-155.

Zeichner, K. (2009). Teacher education and the struggle for social justice. New York, NY: Routledge.

\section{Author Contact}

Baburhan Uzum: uzum@shsu.edu

School of Teaching and Learning, College of Education, Sam Houston State University, 1908 Bobby K. Marks Dr., Huntsville, TX 77341 U. S. A.

Bedrettin Yazan: byazan@ua.edu Curriculum and Instruction, College of Education, The University of Alabama, Bibb Graves Hall 223B, Tuscaloosa, AL 35487-0231 U. S. A.

Netta Avineri: navineri@miis.edu

TESOL/TFL, Middlebury Institute of International Studies at Monterey, 460 Pierce Street Monterey, CA 93940 U. S. A.

Sedat Akayoglu: sakayoglu@gmail.com

Abant Izzet Baysal Universitesi, Egitim Fakultesi, Yabanci Diller Egitimi Bolumu, 14280, Bolu, Turkey 